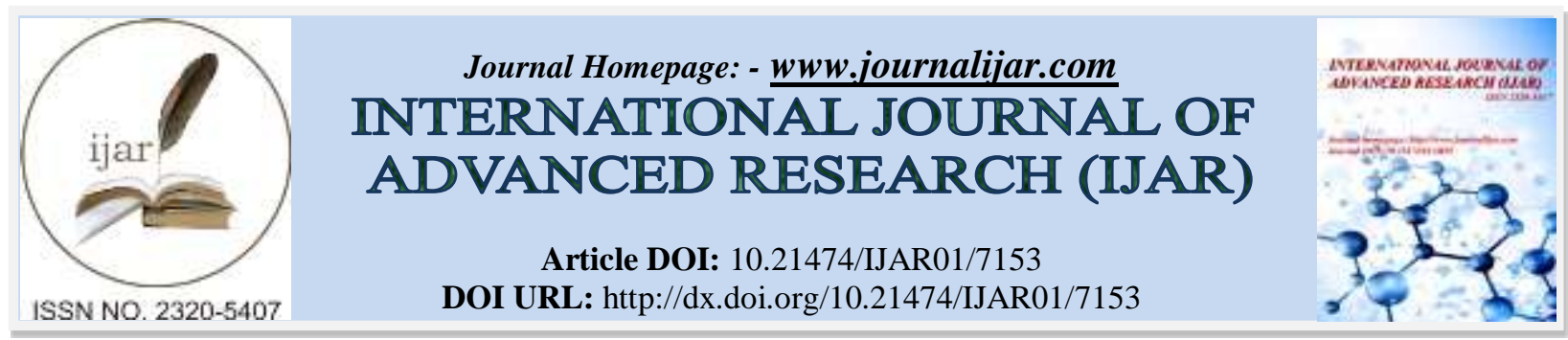

RESEARCH ARTICLE

\title{
A PROSPECTIVE, RANDOMIZED STUDY COMPARING THE ANTIEMETIC EFFECT OF INTRAVENOUS GRANISETRON AND ORAL GABAPENTIN IN PREVENTING POSTOPERATIVE NAUSEA AND VOMITING AFTER MIDDLE EAR SURGERY IN ADULT.
}

Dr. Anuradha Swaminathan Md. Da. And Dr. V. Balakrishnan Md.

1. Associate professor of anaesthesiology, madras medical college, chennai.

2. Assistant professor of anaesthesiology, gmkmch, salem.

\section{Manuscript Info}

Manuscript History

Received: 20 March 2018

Final Accepted: 22 April 2018

Published: May 2018

\section{Abstract}

Aim: To compare the efficacy of prophylactic intravenous administration of Granisetron $3 \mathrm{mg}$ versus Gabapentin $300 \mathrm{mg}$ orally in preventing Postoperative Nausea and Vomiting in patients undergoing middle ear surgeries in adults undergoing general anaesthesia.

Materials and methods: 60 ASA 1 and 2 patients between ages of 18 to 60 yrs, who were scheduled for elective middle ear surgeries under general anaesthesia were included in this study. They were randomly assigned to two groups. Group-1 received $3 \mathrm{mg}$ i.v Granisetron 2 minutes prior to induction and Group B received $3 \mathrm{mg}$ oral Gabapentin I hour before induction. In postoperative period, using visual analogue scale the rate of severity of postoperative nausea were assessed.

Results: Results were analysed by using Chi- Square test and Fisher extract test. By conventional criteria the association between the intervention groups using visual analogue scale to assess postoperative nausea and vomiting is considered to be statistically insignificant since $\mathrm{p}>0.05$ as per unpaired $t$ test

Conclusion: From this study it is concluded that i.v Granisetron and oral Grabapentin groups have equal anti- emetic effect. There is no significant intraoperative and postoperative haemodynamics as well as side effects.

Copy Right, IJAR, 2018,. All rights reserved.

\section{Introduction:-}

Among various surgeries, middle ear surgery is notorious for Postoperative nausea and vomiting. It is more common following general anaesthesia occurring in 30 to $40 \%$ of all patients. It can be prevented by changing anaesthetic technique and relieving patient anxiety preoperatively. Generally, Antiemetic prophylaxis is reserved only for surgeries that have high risk for postoperative nausea and vomiting. Various class of drugs like anti- dopaminergic, anti- cholinergic, butyrophenones, phenothiazines are used to prevent postoperative nausea and vomiting. Dry mouth, extrapyramidal symptoms. Sedation are the side effects expected while using this drug. In this study we are going to compare the antiemetic effect of Granisetron and Gabapentin 


\section{Aim Of The Study:-}

To compare the efficacy of prophylactic intravenous administration of Granisetron 3mg versus Gabapentin $300 \mathrm{mg}$ orally in preventing Postoperative Nausea and Vomiting in patients undergoing middle ear surgeries in adults undergoing general anaesthesia

\section{Materials And Methods:-}

This study was conducted at Madras medical college Hospital during the period of April 2016. After institutional ethical clearance and obtaining the informed consent, 60 ASA 1 and 2 patients between ages of 18 to 60 yrs, who were scheduled for elective middle ear surgeries under general anaesthesia were included in this study. Preoperatively, all patients were taught about the visual analogue scale.

\section{Exclusion criteria:}

Pregnant females, History of addiction or using antiemetics, BMI > 30, Any cerebellar problems, Uncontrolled bleeding during surgery, History of postoperative nausea and vomiting after previous surgery, History of motion sickness, Duration of surgery $>2 \mathrm{hrs}$

\section{Anaesthetic technique:}

The patient were premedicated with $0.01 \mathrm{mg} \mathrm{kg}$ of Glycopyrolate and 2microgram of fentanyl after connecting monitors and securing intravenous line. All patients included in this study were randomly allocated into two groups.(Group-1 and Group-2). Routine monitoring (e.g. ECG, NIBO, SPO2) was instituted.

Group A received $3 \mathrm{mg}$ iv Granisetron ( $3 \mathrm{ml}$ ) prior to induction and Group B received 3mg Gabapentin orally $1 \mathrm{hr}$ before induction. After 5 minutes preoxygenation,patient was induced with $5 \mathrm{mg} \mathrm{kg}$ of $2.5 \%$ iv Thiopentone sodium,intubation was facilitated by giving $0.5 \mathrm{mg} \mathrm{kg}$ Atracurium and ventilated for 5 minutes and then trachea was intubated with cuffed endotracheal tube of appropriate size. Anaesthesia was maintained with intermittent positive pressure ventilation with $60 ; 40$ oxygen and nitrous oxide, $0.8 \%$ to $1.2 \%$ Isoflurane and Atracurium w. Intraoperative haemodynamics were monitored every half an hour for $6 \mathrm{hrs}$ and then every $2 \mathrm{hrs}$. Postoperative nausea and vomiting were assessed using visual analogue scale in the PACU for every half an hour

\section{Severity of vomiting was classified as:}

Mild: 1- 2episodes;

Moderate: 3-4 episodes

Severe: more than 4 episodes

\section{Observations:}

Majority of Gabapentin group patients had a mean heart rate range of 82-108 bpm with mean spo2 of 98-99\%. In Granisetron group patients had a mean heart rate range of $72-100 \mathrm{bpm}$ with mean spo2 of $99-100 \%$. The association between these groups regarding heart rate before and after induction intraoperatively is considered as statistically insignificant $(\mathrm{p}>0.05)$

Majority of Gabapentin group patients had a mean BP range of 119-139181-89 with MAP range 93-106mmHg.In Granisetron group patients had a mean BP range of 114-143/78-90 with MAP range 87-92mmHg. The association between these groups regarding heart rate before and after induction intraoperatively is considered as statistically insignificant $(\mathrm{p}>0.05)$.

\begin{tabular}{|c|c|c|c|c|c|c|c|c|c|c|c|}
\hline \multicolumn{2}{|c|}{$\begin{array}{l}\text { Visual Analogue } \\
\text { scale Postoperative }\end{array}$} & O hr & $1 \mathrm{hr}$ & $1.5 \mathrm{hr}$ & $2 \mathrm{hr}$ & $2.5 \mathrm{hr}$ & $3 \mathbf{h r}$ & $3.5 \mathrm{hr}$ & $4 \mathrm{hr}$ & $4.5 \mathrm{hr}$ & $5 \mathrm{hr}$ \\
\hline \multirow{3}{*}{ 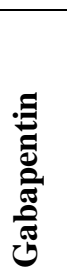 } & $\mathrm{N}$ & 30 & 30 & 30 & 30 & 30 & 30 & 30 & 30 & 30 & 30 \\
\hline & Mean & 0.03 & 0.10 & 0.17 & 0.40 & 0.70 & 0.93 & 1.37 & 1.57 & 1.87 & 2.23 \\
\hline & SD & 0.18 & 0.31 & 0.38 & 0.50 & 0.60 & 0.64 & 0.61 & 0.73 & 0.86 & 1.01 \\
\hline
\end{tabular}




\begin{tabular}{|l|l|l|l|l|l|l|l|l|l|l|l|}
\hline & $\mathrm{N}$ & 30 & 30 & 30 & 30 & 30 & 30 & 30 & 30 & 30 & 30 \\
\cline { 2 - 12 } & Mean & 0.00 & 0.00 & 0.00 & 0.03 & 0.03 & 0.13 & 1.13 & 1.23 & 1.40 & 2.13 \\
\cline { 2 - 10 } & SD & 0.00 & 0.00 & 0.00 & 0.18 & 0.18 & 0.35 & 0.35 & 0.50 & 0.62 & 0.63 \\
\hline $\begin{array}{c}\text { Pn values } \\
\text { Unpaired t test }\end{array}$ & 0.3256 & 0.0831 & 0.0226 & 0.06 & 0.07 & 0.07 & 0.08 & 0.07 & 0.08 & 0.09 \\
\hline
\end{tabular}

By conventional criteria the association between the intervention groups using visual analogue scale to assess postoperative nausea and vomiting is considered to be statistically insignificant since $p>0.05$ as per unpaired $t$ test

\section{Discussion:-}

The optimal anti-emetic regimen for postoperative nausea and vomiting is one which would decrease the incidence of nausea and vomiting without increasing the side effects. Inspite of much attention paid to postoperative nausea and vomiting the optimal anti-emetic regimen in surgical setting has still not been established.

The observation and results revealed that there is no significant difference between Granisetron and Gabapentin group in preventing postoperative nausea and vomiting. This is proved by monitoring intraoperative haemodynamics and by Visual analogue scale. These findings are similar to results previously published studies and meta analysis of randomized controlled studies comparing these studies.

A study done by Mortezab Heidari, Azim Honarm and et al by compared Granisetron and Gabapentin group in preventing postoperative nausea and vomiting after middle ear surgery in adults. And the results showed that there is no significant difference in intraoperative vitals between the two groups as well as visual analogue scale for vomiting.

The present study also revealed that there is no significant difference in intraoperative vitals between the two groups as well as visual analogue scale for vomiting which are all observed for 24 hours.

\section{Conclusion:-}

From this study, it has been concluded that Granisetron and Gabapentin groups have equal anti- emetic effect. Intraoperative and postoperative haemodynamics were also noted among the two groups were found to be insignificant.

\section{Bibliography:-}

1. ApfelCC, Kranke P et al comparison of surgical site and patient history with a simplified risk score for the prediction of postoperative nausea and vomiting. Anaesthesia 2004;59;1078-1082

2. Andrews P.L.R.Physiology of nausea and vomiting Br J Anaesthesia1992

3. Ajori 1 et al Effect of Gabapentin on postoperative pain and nausea and vomiting under abdominal hysterectomy

4. Arif AS et al Postoperative nausea and vomiting- a review. Middle East $\mathrm{J}$ aneasthesia 2001:16;127-54

5. Achuthan $\mathrm{S}$ et al. Gabapentin prophylaxis for postoperative nausea and vomiting in abdominal surgeries.2015:114;588-97.

6. Bunce K.T. The role of 5HT in PONV Br. J ANAESTHESIA1992

7. Fuji et al . Comparison of Granisetron and Droperidol and Metoclopramide in the treatment of established nausea and vomiting after breast surgery 2003:25;1142-9.

8. Kazemi- Kjellberg F et al . Treatment of established postoperative nausea and vomiting 2001;1:2

9. KovacAL.L Prevention and Treatment of postoperative nausea and vomiting drugs 2000;59:213-243

10. Pandey'Sck.ET AL . Prophylactic Gabapentin for prevention of postoperative nausea and vomiting in patients underging laparascopic chlecystectomy 2006;52:97-100 